\title{
CoVid19, a Threat or a Blessing to Globalization?
}

\author{
Daniel Moise ${ }^{1, *}$, Diana Mihaela Negescu Oancea ${ }^{1}$, Amelia Diaconu ${ }^{2}$, and Silviu Diaconu ${ }^{1}$ \\ ${ }^{1}$ Bucharest University of Economic Studies, Bucharest, Romania \\ ${ }^{2}$ Artifex University, Bucharest, Romania
}

\begin{abstract}
.
Research background: The new CoVid19 took by surprise almost all the countries were not aware that encountered the virus. It is most likely that many countries did not even know, realize or were not aware that the virus was already spreading in their homeland. We can consider that it was like a "tornado" or even worse like a "Geo-Storm" that affected almost each country in the World.

Purpose of the article: The healthcare system in each country was caught unprotected to such a large scale of need of medical supplies and devices. The lack of medical supplies showed the dependence of many countries on too few manufacturing countries. The demand for such products was sky rocketing and so did the price for this kind of products.

Methods: The issue studied should not be only for medical supplies, but also for strategic products, or components for example, for air transportation, military purposes, energy supplies, and so on, that could put in real difficulties the economy and the social well-being, as we know it. We have conducted a research among the stakeholders.

Findings \& Value added: The outcome of this pandemic might be the end of Globalization, as the trade and dependency upon other countries will stop, or on the contrary, the consolidation of the Globalization, giving itself even an immense synergy in order to deepen and proliferate. In order to discover and debate this matter, we carried out a research to see and understand.
\end{abstract}

Keywords: CoVid-19 pandemic; globalization; autonomy; dependent; very high demand

JEL Classification: $F 6$; F62; F63

\footnotetext{
${ }^{*}$ Corresponding author: moisedaniel@mk.ase.ro
} 


\section{Introduction and Literature Review}

2019 will always remain in our memory as the year when the World changed irremediable, from all points of view and aspects. Starting from social, cultural and continuing especially with the economic level. After the medical crisis has passed, many scholars consider and predict that an economic crisis will follow, with a greater impact than the crisis from 2008. We can consider that, the appearance of CoVid-19 was like a "tornado", or even worse like a "Geo-Storm" that affected almost each country in the World. The healthcare system in each country was caught unprotected to such a large scale of need of medical supplies and devices. The vulnerabilities of societies to inequalities were accentuated [1] by the new pandemic crisis, especially in the public health field. It is also high time for companies to initiate [2] other CSR programmes in order to help communities to overpass the crisis due to CoVid19.

Although these medical supplies like: face masks, medical suits, surgical gloves; are not hard to produce and the process of the production line is not so complicated, the high demand in such a short period of time resulted in ruptures in the logistic chain. Furthermore, the lack of medical supplies showed the dependence of many countries on too few manufacturing countries. The demand for such products was sky rocketing and so did the price for this kind of products. Due to this respect, many countries, starting with France and the United States of America, began to produce themselves this kind of products, being more than necessary. It can be seen not only as a good and sound strategy, but at the same time securing national safety, as in case of an outbreak, the demand could be satisfied internally, without appealing to producers from other countries.

Another important aspect is the fact that also the raw materials needed to produce those devices, medicine and healthcare equipment, either to be found and extracted from their own country, or to be sure to have sufficient in stocks. Even the prices of raw materials, especially, for medicine grew due to the fact of high demand and even the scarcity worldwide. More than $40 \%$ of the global production of raw materials used [3] for medicine is supplied by China and India, while in Europe, Italy is the main supplier. The first effect was the ban of almost all the medicines, some of them doubling their price or even more. India has forbidden [4] the export of hydroxychloroquine in any kind of its form, raw material, or finite medicine in order to use them for its own population. Under the international pressure [5], India started to export hydroxychloroquine only to foreign governments [6], but not to private companies. What is even more interesting is the fact that $90 \%$ of the substances needed [7] to produce generic medicine comes from China, in comparison with only $50 \%$ of the substances needed by the medicine that are protected by a patent and are supplied by the same country. Even India had problems [8] with the supply of the main chemical ingredients, as more than $70 \%$ of the ingredients is imported from China. In 2019, the total turnover of the big pharmaceutical companies was around [9] 455 billion $\$$ and in 2020 is estimated to have a surplus of more than 138 billion $\$$. As a result of making a quick profit [10], pharmaceutical distributors and even pharmacy networks and not only, added supplementary percentage in order to increase profit. They blame it on the exchange rate, very high demand, as the population started to make their personal stocks, very often without having the prescription from a doctor. The only problem is that medicines have a warranty period, and after they expire, the drugs can do even more harm than good. The opportunity of gaining profit in a short period was practised by some pharmaceutical companies that increased [11] the price of some products, and instead of practising a commercial excess from $1 \%$ up to $50 \%$, they decided to go up to $300 \%$. Unfortunately, some companies went too far, instead of selling genuine medical alcohol, they marketed cleaning solution that lead even to the death [12] of some people. 
The necessity of countries to produce for themselves, starting with the extraction of raw materials, transportation to their own facilities and factories to produce and distribute only for internal consumption of drugs and medical devices, should not be considered just from the economic point of view, but also from national security strategy point of view. Especially in developed [13] countries to construct from scratch the entire logistic chain, can be not only difficult, but also more expensive than appealing to imports. Another important issue can be the fact that the extraction and the production of chemical substances can lead to a greater pollution. The issue studied should not be only for medical supplies, but also for strategic products, or components, for example, for air transportation, military purposes, energy supplies, and so on, that could put in real difficulties the economy and the social well-being of people, as we know it. The outcome of this pandemic might be the end of Globalization, as the trade and dependency upon other countries will stop, or on the contrary, the consolidation of the Globalization, giving itself even an immense synergy in order to deepen and proliferate. The air cargo had [14] a less depression, and in some cases, an increase, especially, regarding the transportation of medical supplies and devices, tests, chemicals and so on, in comparison with the civil aviation that was drastically reduced or even forbidden.

Although Globalization has been regarded as a synergy to increase trade, communication, interconnection, international relations leading to prosperity, spread of technology and innovation, multicultural empathy, development, higher standards of living, environment benefits, decrease of cost production, division of labour and specialization. However, in 2020 due to the worldwide pandemic, Globalization has been seen as [15]: economic dislocation, increasing inequality, unwanted immigration that ease the transmission of the coronavirus. Moreover, during world-wide crises, international cooperation cease to exist, the supply chains can be obstructed bearing in mind that it is quite complicated to fit [16] international interests within national decision making. Policies makers need to have access to accurate and genuine information. But the information must be transmitted by a trustworthy organization as fast as possible, while the lack of it, can increase uncertainty and leave place for misinformation, disinformation and misinformation that are [17] plenty and abundant. The main concern that the countries have, is not about the factories that they have to build but for the raw materials, needed in order to produce this kind of products. One solution to this matter can be to appeal to the rule of the 3 R's [18]: recycle, reuse and reduce.

Companies and NGO's all around the world tried to fulfil the demand for the shortage of medical supplies, preventive materials and medical devices. Notorious companies that used to produce [19] perfumes switched their production towards manufacturing of sanitizer substances, companies from textile field switched to produce face masks and even companies that produce cars switched to produce ventilators.

The European Commission and the United States Food and Drug Administration, outlined [20] regulations for the demand optimization and a rational supply regarding the health and pharmaceutical market. These regulations will have an impact in an equal measure in the short term and in the long term, trying to diminish the effects of: irrational stocking, panic buying, supply shortages, self-sufficiency in pharm-production and trend changes. While Germany and the United States of America are [21] specialized in R\&D of high-tech medical devices, being market leaders suppliers, Malaysia and China were market leaders in manufacturing surgical garment, facemasks and gloves. The real dangers to the international health care system is the fact that many governments will adopt [22] and take nationalist steps as responses to the pandemic, with little regard towards other countries, and to the matter that pandemics are not restrained by borders and what is even worse, regarding CoVid-19, it can re-infect a person who already had the virus. The international 
community is forced [23] to immediate increase security focus on global health, in order to pass over not only the Coronavirus pandemic, but also future threats.

\section{Research Methodology}

In order to discover and debate these important matters, like internal or external production of medical supplies, substances, devices and even the impact of Globalization, we carried out a qualitative research to see and understand the attitude of the stakeholders regarding the problems raised. We used in-depth interviews, as a focus group would have been problematic due to the restrictions and at the same time, the fear of the subjects to be in a room together. The panel was constituted by 15 people, with age range from the youngest 19 up to the oldest 67 . In order to have a complete view of the perceived situation and aspects, the subjects are students or employees in private or public sector like: doctors, pharmacists, teachers, police officers, entrepreneurs, military personnel, directors, company administrators, people working in multinational companies, couriers, engineers, accountants, trainers, bartenders, installers and so on.

The interview was structured in three modules:

\section{1) How has the CoVid-19 pandemic affected your lives?}

All of the respondents answered that their lives changed in a bigger or smaller degree. Those working in HORECA industry were sent in technical unemployment, the doctors, police officers and pharmacists were put to very hard test and had to work even 24/7 especially at the beginning of the pandemic. In the same manner the couriers are under immense pressure due to the restrictions of the population that were not allowed not to go abroad, but only to go out to buy their groceries. Even businesses have changed as, on the contrary of the initial expectations, people started to invest more in the comfort of their homes. The prices not only for medical supplies have risen due to their lack and shortages, as well as for other products, being a domino chain due to the new regulations regarding safety. The white collars started to preponderantly work from home. Even some famous multinational companies like Google or Facebook and not only, allowed their employees to work from home up to the end of the year, with the possibility of extending this period, with the regard of the evolution of the pandemic. Even the buying habits have changed; some of the respondents claimed that doing shopping together was a family action, now they are no longer doing like that. The buying frenzy affected almost all of them, especially for food and hygiene products, being misled by the information and the news from other countries where there were presented the empty shelves in the shops and also because some hypermarkets and supermarkets started to limit the quantity that a buyer was allowed to purchase at a visit. Even the purchase of the PPE's, was problematic and in many cases the price has risen even than more 100 times. In addition, some absurdities occurred as customers were not allowed to enter the stores without a mask, although they mentioned their purchase intention of one from that store. Due to the news on TV and social media, most of them started to stock medicines that were not related to coronavirus, but to their own illness.

2) Should the production of products, mainly, sensitive products like PPE's (personal protective equipment: surgical masks, gowns, gloves, disposable medical shoe covers), medicines, medical devices and other types of products be manufactured internally or externally?

Only the chemists and doctors enumerated traditional countries that manufactured PPE's mentioning China, Vietnam, Thailand and for high tech devices countries like Japan, USA, UK, Germany, Canada, Netherlands and Israel. The rest of the respondents mentioned especially China for PPE's and the USA for high tech devices. None of them ever heard of the internal production of any of these products, but they consider a good and 
sound strategy of internally producing especially, with a view to satisfying the need for these kinds of commodities within the borders of their countries. Even more, one of them suggested that it is not only a good and sound strategy for the government to adopt this kind of strategies in the long term, but it is also a patriotic and nationalist thing. He even proposed that this strategy should be extended, not only to military and transportation sector, but also in the case of the utilities, as energy, water, gas and communication. The logic was very simple: "What will happen if you want to go to war with the country that supplies you with weapons?"

\section{3) Is the Future of Globalization under threat or it is the starting point to develop even furthermore?}

At this point, most of the participants argued that Globalization is under threat and mentioned some causes, then they complained how business was done in the time of the healthcare crisis when contracts were not respected, prices have sky rocketed and furthermore it was not ethical and moral for the breach of the contracts, modifying the prices, exceeding the deadline, or even suspending or cancelling the orders, especially, for medical supplies. Some of the respondents have mentioned that they will begin to boycott the products manufactured abroad, like stop buying them and purchasing only from their internal producers. This has occurred as in many cases, the surgical face masks did not obey any kind of standards, doing, unfortunately, more harm than good. The construction of factories will not come only with the benefits of increasing national security, creating new jobs by producing PPE's and military equipment, but also causing pollution. Greece and Spain were given as examples of countries that succeeded in developing their own test for discovering Coronavirus with a high degree of accuracy. It is also desirable that the entire logistic chain should be in the hands of the government, and in case of the extraction of raw materials is not possible in their own countries, they should to use either foreign suppliers, or the 3 R's: reuse, reduce \& recycle. The main issue still stands that countries have to raise their own autonomy and independence.

Most of the respondents have the opinion that, although CoVid-19 pandemic made countries at the beginning of the crisis behave selfishly, after the "Geo-storm" or "the uncertainty of the unknown" diminish caused countries to come together.

Limitations of the research conducted can be due to the fact that it is a qualitative research and not a quantitative one. Another reason can reside from the circumstance that it was a transversal research and not longitudinal, as the perceived attitude can change due to the conditions offered at a certain time. Furthermore, a quantitative research can be simultaneous deployed in several countries in order to discover what are the main factors that contribute to accepting Globalization, or, on the contrary, to reject it.

\section{Conclusions and Discussions}

Adaptation can be the key to the need of the increase in worldwide trade, and so many international airlines converted [14] passenger aircrafts to cargo aircrafts, as in some countries there is a deficiency of international cargo need. Many social, cultural and economic dynamics will change after the pandemic has ceased, conducting [11] to a reorganization of heath care services around the world, the emphasis will be on collaboration, un-breach-able contracts and mutual trust. Some countries do not have [24] enough resources to conduct testing on their population, let alone managing this pandemic, while, on the other hand the politicians [25] are perusing their own political agenda. An important role must be given and should have the governments, which must rely their decisions on sound science and not giving in to populism, political pressure, or lobby made by private or public organizations. They must bear [5] in mind that their decision should be made in favour of the people they lead and, even more especially, the patient care and 
public health. For future avoidance [15] of this, the periods of shortages in medical supplies and technologies can be refrained from by using the Pareto principle, $20 / 80$, and not depending on only one provider. The main issue is that countries worldwide should not have recourse to national competition, but to international cooperation and understanding. In the past humankind handled, similar crises like the Spanish flu, Ebola suggesting that the Earth will also finally recover from the Corona-Virus Pandemic. After all, Globalization is desirable and a good thing towards all the parties implied and most importantly, their relationships should be trustworthy. After the pandemic has gone, the problem will persist for being dependent on another country, or being autonomous. But this will be revealed to us after a vaccine or treatment that works are going to be discovered.

\section{References}

1. Bapuji H., Patel C., Ertug G., Allen D.G., (2020). Corona Crisis and Inequality: Why Management Research Needs a Societal Turn. Journal of Management, 46(7). https://journals.sagepub.com/doi/full/10.1177/0149206320925881

2. Barnett, M.L., Henriques I., Husted, B.W. (2020). Beyond Good Intentions: Designing CSR Initiatives for Greater Social Impact. Journal of Management, 46(6), 937-964. https://journals.sagepub.com/doi/abs/10.1177/0149206319900539?journalCode=joma

3. Momaya, K.S. (2020). Return from COVID-19: Thinking Differently About Export Competitiveness and Sustainability. International Journal of Global Business and Competitiveness, 15, 1-9.

4. Merrin, W. (2020). Anthropocenic war: coronavirus and total demobilization. Digital War.

5. Singh, J.A., Ravinetto, R. (2020). COVID-19 therapeutics: how to sow confusion and break public trust during international public health emergencies. Journal of Pharmaceutical Policy and Practice, 13, 47.

6. Rajesh R. (2020). India Again Allows Export of Antimalarial Drug Touted for Coronavirus. WSJ. https://www.wsj.com/articles/india-again-allows-export-ofantimalarial-drug-touted-for-coronavirus-11586257292

7. Trump, B.D., Linkov, I. (2020). Risk and resilience in the time of the COVID-19 crisis. Environment Systems and Decisions, 40, 171-173.

https://link.springer.com/article/10.1007/s10669-020-09781-0

8. Milani, F. (2020). COVID-19 outbreak, social response, and early economic effects: a global VAR analysis of cross-country interdependencies. Journal of Population Economics, 223-252.

9. Greener, I., (2020). The changing governance of welfare: revisiting Jessop's framework in the context of healthcare. Social Theory \& Health, Early access.

10. Koh, A.H. C., Koh, L.R., Sheu, S.J., Sakamoto, T. (2020). What COVID-19 has taught us: lessons from around the globe, Graefe's Archive for Clinical and Experimental Ophthalmology, 258(10), 2091-2094.

11. Ceylan, R.F., Ozkan, B., Mulazimogullari, E. (2020). Historical evidence for economic effects of COVID-19. The European Journal of Health Economics, 21(6), 817-823.

12. Gangemi, S., Billeci, L., Tonacci, A. (2020). Rich at risk: socio-economic drivers of COVID-19 pandemic spread. Clinical and Molecular Allergy, 18, 12.

13. Aslam, F., Aziz, S., Nguyen, D.K., Mughal, K.S., Khan, M. (2020). On the efficiency of foreign exchange markets in times of the COVID-19 pandemic. Technological Forecasting and Social Change, 161, 120261. 
14. Li, T. (2020). A SWOT analysis of China's air cargo sector in the context of COVID19 pandemic. Journal of Air Transport Management, 88, 101875.

15. Kobrin, S.J. (2020). How globalization became a thing that goes bump in the night. Journal of International Business Policy, 3, 280-286.

16. Elliott, R.J.R., Schumacher, I., Withagen, C. (2020). Suggestions for a Covid-19 PostPandemic Research Agenda in Environmental Economics. Environmental and Resource Economics, 76(4), 1187-1213.

17. Baines, D., Elliott, R.J.R. (2020). Defining misinformation, disinformation and malinformation: An urgent need for clarity during the COVID-19 infodemic. Ideas. https://ideas.repec.org/p/bir/birmec/20-06.html

18. Heek, J., Arning, K., Ziefle, M. (2017). Reduce, reuse, recycle: Acceptance of CO2utilization for plastic products. Energy Policy, 105, 53-66.

https://www.sciencedirect.com/science/article/pii/S0301421517300915?casa_token=s

MgFhVqy6UIAAAAA:LbHPJUAveJoNJZeSGYHGJ81h0fOpsD7rLmF0951X2pLFeO 6U47sAuBVAfI2qF4k7ao83Egph7exx\#f0010

19. Hiscott, J., Alexandridi, M., Muscolini, M., Tassone, E., Palermo, E., Soultsioti, M., Zevini, A., (2020). The global impact of the coronavirus pandemic. Cytokine \& Growth Factor Reviews, 53, 1-9.

https://www.ncbi.nlm.nih.gov/pmc/articles/PMC7254014/

20. Ayati, N., Saiyarsarai, P., Nikfar, S. (2020). Short and long term impacts of COVID-19 on the pharmaceutical sector. DARU Journal of Pharmaceutical Sciences. Early access.

21. Gereffi, G. (2020). What does the COVID-19 pandemic teach us about global value chains? The case of medical supplies. Journal of International Business Policy, 3, $287-$ 301.

22. Strange, R. (2020). The 2020 Covid-19 pandemic and global value chains. Journal of Industrial and Business Economics, 47, 455-465.

23. Metelmann, I.B., Flessa, S., Busemann, A. (2020). Does health securitization affect the role of global surgery? Journal of Public Health. Early access.

24. Yamin, M. (2020). Counting the cost of COVID-19. International Journal of Information Technology, 12, 311-317.

25. Mills, P. (2020). Background discussion paper COVID-19 antibody testing and 'immunity certification': a discussion paper. Nuffieldbioethics. https://www.nuffieldbioethics.org/assets/pdfs/Discussion-paper-COVID-19-antibodytesting-and-immunity-certification.pdf 